\title{
Evaluation of Passive Islanding Detection Methods for Line to Ground Unsymmetrical Fault in Three Phase Microgrid Systems
}

\author{
Microgrid Islanding Detection Method
}

\author{
L. Bangar Raju \\ Electrical and Electronics Engineering Department \\ Koneru Lakshmaiah Educational Foundation \\ Guntur, India \\ 1smlbr@yahoo.in
}

\author{
K. Subba Rao \\ Electrical and Electronics Engineering Department \\ Koneru Lakshmaiah Educational Foundation \\ Guntur, India \\ principal.coe@kluniversity.in
}

\begin{abstract}
Distributed Generators (DGs) are incorporated in the power distribution systems to develop green energies in microgrids. Islanding is a challenging task in a microgrid. Different types of islanding methods, e.g. local and remote methods, have been developed for handling this task, with local methods being easier to implement, while remote methods are communication-based and costly. The local methods are classified as passive, active, and hybrid, out of which the passive methods are more simple and economical. In this paper, a passive islanding detection method is proposed to detect single line to ground fault. This fault is considered to represent the 60 to $70 \%$ of the total un-intentional faults of this category. The available passive methods cannot detect islanding at lower power mismatches as the variations in voltage and frequency fall within thresholding values. In this method, the voltage signals are first retrieved at the targeted DG output and then the phase angle is estimated. Finally, the phase angle is differentiated to get Rate Of Change Of Voltage Phase Angle (ROCOVPA) to detect islanding, and then it is compared with the Rate Of Change Of Frequency (ROCOF) at zero percent power mismatch. Simulation results depict that the ROCOVPA is more effective than ROCOF. The proposed method not only reduces detection time and NonDetection Zone (NDZ) but is also stable during non-islanding cases like load connection and disconnection to avoid nuisance tripping.
\end{abstract}

Keywords-distributed generation; non detection zone; point of common coupling; ROCOVPA; ROCOF; line to ground fault

\section{INTRODUCTION}

During the normal mode, a microgrid is in synchronism with the main grid feeding the connected loads and importing the mismatch power of the load from the grid. Based on load demand, the mismatched power is supplied by the grid. But during unintentional unsymmetrical faults on the system, the microgrid has to detect the fault condition and isolate itself from the main grid within $2 \mathrm{~s}$ as per IEEE-1547-2018 regulations. There are symmetrical and unsymmetrical faults, but in this paper only unsymmetrical single line to ground fault was tested as the majority of faults are of this nature. The different islanding detection methods have their own advantages and disadvantages. The active methods affect the power quality due to perturbations during testing. The passive methods fail to detect islanding at lower power mismatches due to the smaller variation in voltage and frequency above threshold. The hybrid methods are good to detect islanding but power quality problems arise due to injections of perturbations. Communication methods are good with a smaller Non Detection Zone (NDZ) but are costly. The implementation of such methods depends on the size of the microgrid and the criticality of loads.

To mitigate these problems, in this paper the Rate Of Change Of Voltage Phase Angle (ROCOVPA) method is proposed which detects islanding at zero percent mismatch power and also avoids nuisance tripping during non-islanding operations like load connection and disconnection. A simple methodology is used. At first, the voltage phase angle is calculated at the output of DG and then differentiated to get the ROCOVPA to detect islanding. In normal conditions, when there is no fault, the variations are within the threshold values but during fault conditions the variations exceed the threshold values to island the microgrid safely from the main grid within $2 \mathrm{~s}$. The DG feeds the connected load in droop control in islanded mode, without any power interruption to load.

The proposed ROCOVPA methodology can be extended to detect symmetrical and unsymmetrical faults. In this paper, the ROCOVPA is tested and compared with the Rate Of Change Of Frequency (ROCOF) method in Matlab/Simulink, in which ROCOVPA is proved to perform better. As per the result analysis, the proposed ROCOVPA method detects islanding at even zero percent mismatch power $(0 \% \mathrm{NDZ})$. The testing is extended for non-islanding cases during load connection and disconnection for stability. The ROCOVPA method is proved to be stable during non-islanding cases and also avoids nuisance tripping.

The comparison of the proposed ROCOVPA method with ROCOF proves that it is better in discriminating islanding and non-islanding operations with less NDZ and detection time. 


\section{NETWORK AND MATHEMATICAL MODEL}

The network model is shown in Figure.1. The ROCOVPA islanding detection method is tested on a DG with $2.5 \mathrm{KW}$ with an interfaced inverter. A parallel RLC load is connected to the DG with a quality factor of 1.8 at the Point of Common Coupling (PCC). The DG inverter is connected to the main grid to the PCC through a 3-phase circuit breaker. The inverter is connected to the PCC with filter values: $C f=2 \mu F, L f=2 m H$, and $R f=10 \Omega$.

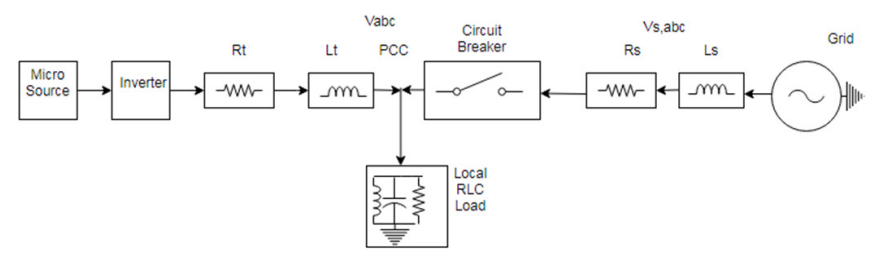

Fig. 1. Network model of the islanding detection ROCOVPA method.

The mathematical model of the islanded microgrid in the $a b c$ frame is given by the following equations:

$$
\begin{gathered}
V_{t, a b c}=L_{t} d \frac{i_{t, a b c}}{d t}+R_{t} i_{t, a b c}+V_{a b c} \\
i_{t, a b c}==V a b c / \mathrm{R}+i_{\mathrm{L}, a b c}+C \frac{d}{d t} V a b c \\
V_{a b c}==L d / d t+i_{L, a b c}+R_{L} i_{L, a b c}
\end{gathered}
$$

where $V_{t, a b c}, V_{a b c}, i_{t, a b c}$, and $i_{L, a b c}$ are the terminal's phase voltages and currents respectively of the inverter at the PCC.

These three-phase instantaneous voltages and currents are to be transformed to the synchronous rotating frame $d q 0$ in order to have control of active power (d-axis) and reactive power (q-axis), to keep mutual inductance constant, to achieve the desired output, to have infinite gain control on PI, PID, by adjusting integrators, and to make steady state error to zero to make computations easy.

$$
\begin{gathered}
X(t)=A X(t)+B u(t) \\
y(t)=C X(t) \\
u(t)=V_{t d}
\end{gathered}
$$

$A, B, C$, and $D$ are constants given by:

$$
A=\left[\begin{array}{ccccc}
\frac{-R t}{L_{t}} & \omega_{0} & 0 & \frac{-1}{L_{t}} & \\
\omega_{0} & \frac{-R_{t}}{L} & -2 \omega_{0} & \frac{R l C \omega_{0}}{L} & -\frac{\omega_{0}}{R} \\
0 & \omega_{0} & \frac{-R l}{L} & \frac{1}{L}-\omega_{0}{ }^{2} C & \\
\frac{1}{C} & 0 & \frac{-1}{C} & -\frac{1}{R C}
\end{array}\right]
$$

$$
\begin{gathered}
B^{T}=\left[\begin{array}{llll}
\frac{1}{L_{t}} & 0 & 0 & 0
\end{array}\right] \\
C=\left[\begin{array}{llll}
0 & 0 & 0 & 0
\end{array}\right] \\
D=\left[\begin{array}{lll}
0 & (8)
\end{array}\right. \\
X^{T}=\left[\begin{array}{llll}
i_{t d} & i_{t q} & i_{L d} & V_{d}
\end{array}\right]
\end{gathered}
$$

These equations give the transfer functions of $V_{d} / V_{t d}$, where $V_{d}$ and $V_{t d}$ are the input and output components of the d axis.

\section{NON DETECTION ZONE}

The efficacy of islanding detection depends on minimizing the NDZ $[4,5]$. The method depends on the percentage of active power mismatch, which as per IEEE-1547 has to be smaller than $15 \%$ and the detection time has to be less than $2 \mathrm{~s}$. The network for the study of NDZ is shown in Figure 2. The DG is connected to the grid through an interfacing inverter, the PCC, and a utility switch [6]. The 3-phase parallel RLC load is connected at the PCC [7].

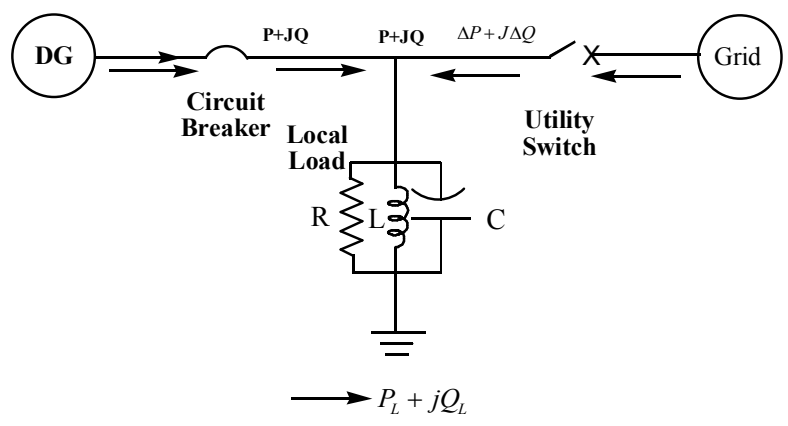

Fig. 2. DG network connected with the grid system.

Equations (12) and (13) give the voltage and frequency at the PCC:

$$
\begin{gathered}
P+\Delta P=\frac{v^{2}}{R} \\
Q+\Delta Q=\frac{V^{2}}{2 \pi f L} \\
V=\sqrt{R(P+\Delta P)} \\
f=\frac{V^{2}}{2 \pi L(Q+\Delta Q)}
\end{gathered}
$$

In islanding conditions, $\Delta P$ and $\Delta Q$ become zero, as there is no main grid. The under/over voltage protection (UVP/OVP) and under/over frequency protection (UFP/OFP) methods are very simple and incorporated in all grid connected inverters and relays connected with DG system protection. In these 
methods, the voltage and frequency are both constantly monitored at the PCC $[1,8]$, where:

$$
\begin{aligned}
& \Delta P=P_{L O A D}-P_{D G} \\
& \Delta Q=Q_{L O A D}-Q_{D G}
\end{aligned}
$$

If $\Delta P \neq 0$, then the voltage at PCC will fluctuate from the normal level, which is an indication of islanding condition. If $\Delta Q \neq 0$, then the frequency at PCC will fluctuate from the normal level, which is an indication of islanding condition. Both these islanding detection methods leave behind a large NDZ. The islanding detection may fail, when $\Delta P$ and $\Delta Q$ are close to zero [8].

Voltage $V^{\prime}$ and frequency $f^{\prime}$ under islanding mode are given by:

$$
\begin{array}{r}
V^{\prime}=\sqrt{R(P)}(18) \\
f^{\prime}=\frac{\mathrm{V}^{\prime 2}}{2 \pi L(Q)}=\frac{\mathrm{RP}}{2 \pi L(Q)}
\end{array}
$$

With these, the voltage and frequency deviations due to power mismatches are given by:

$$
\begin{gathered}
\Delta V=V^{\prime}-V=\sqrt{R(P)}-\sqrt{R(P+\Delta P)} \\
\Delta f=f^{\prime}-f=\frac{\mathrm{V}^{2}}{L(Q)}-\frac{\mathrm{V}^{2}}{L(Q+\Delta Q)}=\frac{\mathrm{R} \times \mathrm{P}}{L \times Q}-\frac{\mathrm{R} \times(\mathrm{P}+\Delta P)}{L \times(Q+\Delta Q)}
\end{gathered}
$$

Equations (20) and (21) show the variations in voltage and frequency due to power mismatch [2]. If the power mismatch is substantial, the variations in voltage and frequency can be identifiable. If the mismatch is too small (less than 15\%) the islanding cannot be detected and hence the formation of the NDZ. Figure 4 shows the NDZ for different power mismatch percentages $[8,9]$. When the reference value is $88 \%$ and $110 \%$ (as per Table I), under / over voltage and grid RMS Voltage $V_{g}$ $=415 \mathrm{~V}$, then $\operatorname{Vmax}=456 \mathrm{~V}$ and $\operatorname{Vmin}=365 \mathrm{~V}$. The schematic diagram of the grid-connected microgrid is shown in Figure 3. The inverter gate pulses take the feedback grid voltage and the set reference. The trigger pulses are given to the inverter accordingly and the output voltage is controlled. The PV is connected to the buck/boost converter to have control on DC reference voltage. The DC/DC converter is connected to the interfacing inverter. The inverter is connected to the PCC via a low pass filter LCL. The microgrid is connected to the grid via a circuit breaker, so that the microgrid can be islanded during faults. A local parallel RLC load is connected to the microgrid at the PCC and the microgrid feeds this local load from the DG, even in the absence of grid.

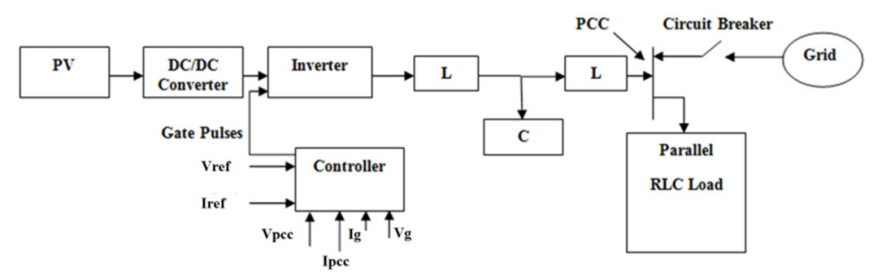

Fig. 3. Schematic diagram of the grid-connected micorgrid.
$\mathrm{NDZ}$ is the operating region in which islanding detection methods cannot detect islanding as specified by IEEE-1547. It is expressed in terms of \% power mismatch or in terms of parameters of the load like $R, L$, and $C$. The NDZ of OVP/UVP and OFP/UVP islanding schemes are shown in Figure $4[10$, 11]. These techniques fail to detect islanding in mismatched power less than $15 \%$. In a distribution network, voltage values, as per standards are between 0.88 p.u. and 1.1p.u. for voltage relays. These voltage levels are equivalent to $\mathrm{DV}=0.12 \mathrm{p} . \mathrm{u}$. and $\mathrm{DV}=0.1$ p.u. respectively. The calculated power mismatch for our test network (the inverter rated output power is $2.5 \mathrm{KW}$ ) are $0.3 \mathrm{KW}$ and $0.25 \mathrm{KW}$ respectively.

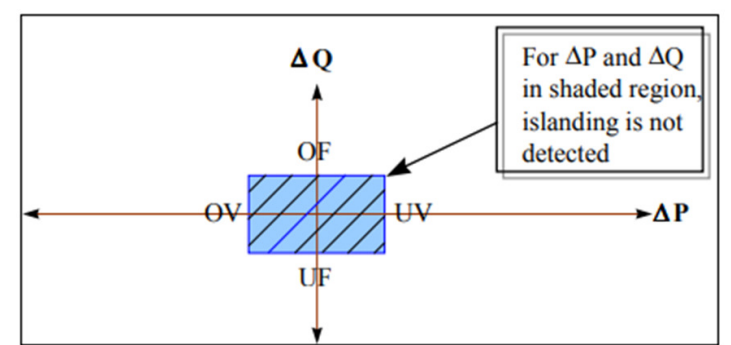

Fig. 4. Mapping of the NDZ in $\Delta P$ versus $\Delta Q$ for OVP-UFP relays.

In grid mode, the load consumes the reactive power [12]. But in islanding mode, DGs cannot inject reactive power to the load, as DGs operate at unity power factor, because the load behaves like a resistance [13], since the load resonance frequency is equal to the system frequency at the PCC. Hence, to find more deviations in frequency, the load selected is parallel RLC with a high quality factor of 1.8 in islanding mode $[14,15]$. The quality factor is given by:

$$
Q_{f}=\omega_{0} R C=\frac{R}{\omega_{0} L}=R \sqrt{\frac{c}{L}}
$$

where $\omega_{0}=2 \pi f_{0}=\frac{1}{\sqrt{L C}}$.

Equation (20) gives the energy stored in the RLC circuit. High quality factor loads have high capacitance and small inductance with or without a high parallel resistance $[16,17]$. The islanding detection is complex with resonant frequency loads of higher quality factor $[18,19]$. The percentage mismatch is not the criterion for load parameters [20,21]. The load reactive power is given by:

$$
Q_{\text {Load }}=\operatorname{Vrms}^{2}\left[\frac{1}{\omega L}-\omega c\right]=\Delta Q
$$

Equation (21) depicts the variation in reactive power for different values of $L$ and $C$. The $\%$ mismatch power for OVP/UVP and OFP/UFP relays is shown in Figure 3 and is given by the equations for active power imbalance:

$$
\begin{gathered}
\Delta P=3 V \times I-3(V+\Delta V) \times I=-3 \times \Delta \mathrm{V} \times I \\
\Delta Q=3 \frac{V^{2}}{\omega_{n} L}\left(1-\omega^{2} L C\right)=3 \frac{V^{2}}{\omega_{n} L}\left(1-\frac{\omega_{n}^{2}}{\omega_{r}^{2}}\right)
\end{gathered}
$$

where $\omega_{n}$ and $\omega_{r}$ are system and resonance frequencies [22, 23]. The system frequency varies until it reaches the resonant frequency of the load in islanding mode and is given by: 


$$
\omega_{r=} \frac{1}{\sqrt{L C}}
$$

and the reactive power imbalance is given by:

$$
\Delta Q=3 \frac{V^{2}}{\omega_{n} L}\left(1-\frac{f_{n}^{2}}{\left(f_{n \pm \Delta f}\right)^{2}}\right)
$$

where $f_{n}$ is the nominal frequency.

The different islanding standards are shown in Table I. The frequency range as per IEEE-1547-2018 is between 49 and $51 \mathrm{~Hz}$, the voltage is between 365 and $456 \mathrm{~V}$ and the range of the parameter $\Delta V=V^{\prime}-V$ is not considered as the case of zero power mismatch is considered [24]. In this case, the voltage fluctuations will not cross the limits. But in other cases, when load active power $P_{L}>$ generated active power $P_{G},(-15 \%)$ or $P_{L}<P_{G}(+15 \%)$ the voltage suddenly goes down or up respectively.

TABLE I. ISLANDING STANDARDS

\begin{tabular}{|c|c|c|c|c|}
\hline Standard & $\begin{array}{c}\text { Detection } \\
\text { time (s) }\end{array}$ & $\begin{array}{c}\text { Quality } \\
\text { factor }\end{array}$ & $\begin{array}{c}\text { Trip frequency range, } \\
\text { nominal frequency } \boldsymbol{f}_{\mathbf{0}} \\
\text { (Hz) }\end{array}$ & $\begin{array}{c}\text { Trip voltage } \\
\text { range (V) }\end{array}$ \\
\hline IEC 62116 & $\mathrm{t}<2$ & 1 & $f_{0}-15 \leq f \leq f_{0}+1.5$ & $0.88 \leq V \leq 1.15$ \\
\hline Korean & $\mathrm{t}<0.5$ & 1 & $59.3 \leq f_{0} \leq 60.5$ & $0.88 \leq V \leq 1.10$ \\
\hline $\begin{array}{c}\text { IEEE-1547- } \\
2018\end{array}$ & $\mathrm{t}<2$ & 1 & $58.8 \leq f_{0} \leq 61.2$ & $0.88 \leq V \leq 1.10$ \\
\hline $\begin{array}{c}\text { IEEE-929- } \\
2000\end{array}$ & $\mathrm{t}<2$ & 2.5 & $59.3 \leq f_{0} \leq 60.5$ & $0.88 \leq V \leq 1.10$ \\
\hline
\end{tabular}

\section{THE PROPOSED METHOD OF ISLANDING DETECTION}

The proposed method can detect islanding at zero \% power mismatch and the detection time is less than in ROCOF. In this method, at first the voltage phase angle is measured at the targeted DG and then the rate of change of voltage phase angle is calculated to detect the islanding phenomenon. In nonislanding condition, the rate of change of the phase angle is negligible after certain time but in islanding this becomes substantial and the islanding is detected. ROCOVPA also avoids nuisance tripping, thus protecting the stability of the microgrid.

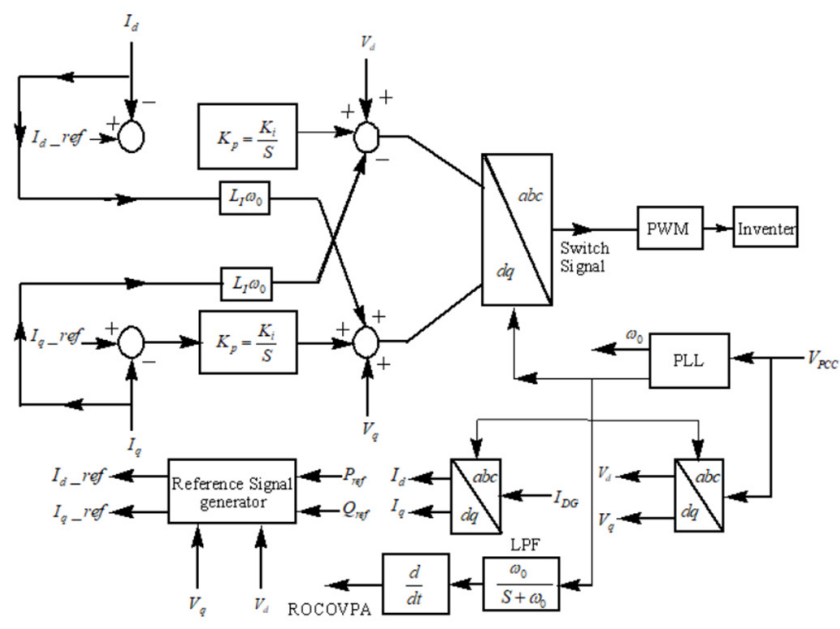

Fig. 5. Current controller block diagram.
The ROCOVPA method is tested with the $2.5 \mathrm{KW}$ DG with a current control mode inverter connected to an RLC load with 1.8 quality factor. Figure 5 shows the current control mode to control the active and the reactive power of the load. In the proposed method, the variation of voltage phase angle is monitored at the specified DG. If there is a change in the voltage phase angle, the rate with respect to time is calculated. During the islanding, the deviations of the rate of change of the phase angle exceed the threshold in order to detect the islanding condition. If the relay threshold is fixed, then the trip command to circuit breaker can be initiated.

The algorithm of the proposed ROCOVPA method of islanding detection is shown in Figure 6. The voltage phase angle at the DG is measured first. After the measurement of the phase angle of the voltage, the rate of change of voltage phase angle is calculated. In a normal situation this value is smaller than $1 \mathrm{deg} / \mathrm{sec}$ (fixed threshold value) but during islanding, the value suddenly crosses the threshold, depending upon the fault severity, by means of which the islanding is detected. During the non-islanding mode this value is in limit, hence nuisance tripping is avoided.

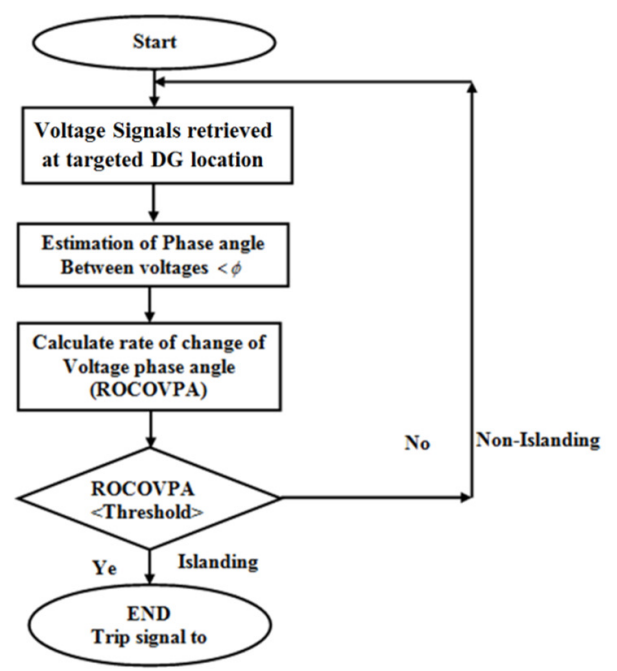

Fig. 6. Flow chart of the proposed ROCOVPA.

\section{DESIGN PARAMETERS OF THE INVERTER}

The proposed ROCOVPA method was tested on the network shown in Figure 1 with the parameters given in Table II. The DG capacity with interfaced inverter is $2.5 \mathrm{KW}$. The interfaced inverter is connected to the main grid through a breaker via the PCC. A 3-phase parallel RLC load is connected at the PCC. The input DC Voltage to the inverter is $500 \mathrm{~V}$. The output line to line voltage of the inverter is $380 \mathrm{~V}$. The line resistance and inductance are $1.5 \mathrm{~m} \Omega$ and $2 \mathrm{mH}$ respectively. The nominal grid frequency is $50 \mathrm{~Hz}$. The inverter carrier frequency is taken as $1 \mathrm{KHz}$. The load parameters with a quality factor of 1.8 are: $R_{L}=1.76 \mathrm{~m} \Omega, L_{L}=3.2 \mathrm{mH}, C_{L}=3.2 \mu \mathrm{F}$. The load resonant frequency is $50 \mathrm{~Hz}$. Current controller gains are $K_{p}=0.4$ and $K_{i}=500$. 
TABLE II. SIMULATION INVERTER PARAMETERS

\begin{tabular}{|l|c|}
\hline \multicolumn{1}{|c|}{ Component } & Value and units \\
\hline DG power & $2.5 \mathrm{KW}$ \\
\hline Switching frequency & $10 \mathrm{KHz}$ \\
\hline DC input voltage & 500 \\
\hline Line voltage & $440 \mathrm{~V}$ \\
\hline Filter capacitance $C_{f}$ & $2 \mu \mathrm{F}$ \\
\hline Filter inductance $L_{f}$ & $5 \mathrm{mH}$ \\
\hline Damping resistance $R_{f}$ & $10 \mathrm{hms}$ \\
\hline Nominal frequency & $50 \mathrm{~Hz}$ \\
\hline Load resistance $R_{L}$ & $1.76 \mathrm{~m} \Omega$ \\
\hline Load inductance $L_{L}$ & $3.2 \mathrm{mH}$ \\
\hline Load capacitance $C_{L}$ & $3.2 \mu \mathrm{F}$ \\
\hline Load quality factor $Q$ & 1.8 \\
\hline Load resonant frequency $f_{r}$ & $50 \mathrm{~Hz}$ \\
\hline Current controller proportional gain, $k_{p}$ & 0.4 \\
\hline Current controller integral gain, $k_{i}$ & 500 \\
\hline
\end{tabular}

\section{RESULTS, ANALYSIS, AND DISCUSSION}

The designed network was tested in Matlab/Simulink for the islanding case of unintentional unsymmetrical L-G fault and non-islanding cases of connection and disconnection of non-linear load. The Matlab Simulation results of ROCOVPA and ROCOF were compared. It was proved that ROCOVPA is better than ROCOF. The proposed method was tested and compared with ROCOF for the islanding case of unintentional unsymmetrical L-G fault at $0 \%$ power mismatch. In this section the simulations are discussed for both ROCOVPA and ROCOF.

\section{A. Islanding Case for Unsymmetrical Fault}

An L-G unsymmetrical fault was initiated on the system at the PCC at $0.4 \mathrm{~s}$ at $0 \%$ power mismatch. $P_{L}=P_{G}$ is the condition for $0 \%$ power mismatch and at that load, a single line to ground fault was initiated on the grid side at $0.4 \mathrm{~s}$. The simulation graph is shown in Figure 7.

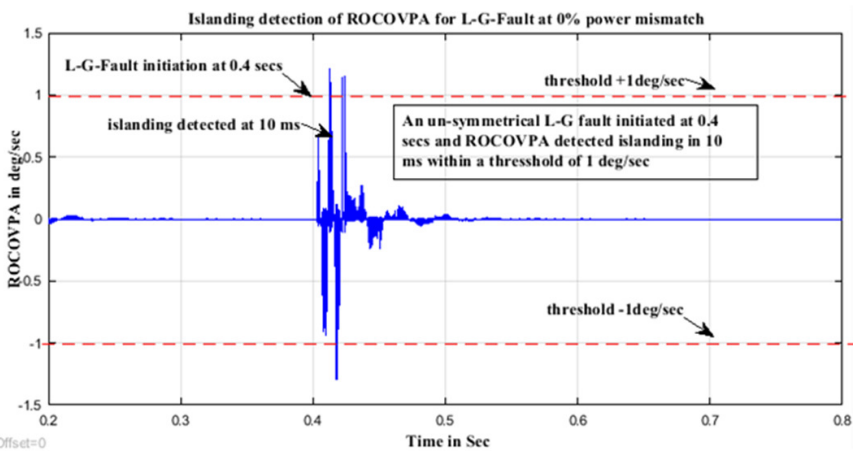

Fig. 7. Islanding detection of ROCOVPA for a L-G fault on the system.

The proposed ROCOVPA detected islanding in $10 \mathrm{~ms}$ within a fixed threshold of $1 \mathrm{deg} / \mathrm{s}$ and the relay exactly detected and sent command to trip the circuit breaker to bring the microgrid to islanding mode from the grid mode. The total time is the sum of relay time and breaker time. Any type of fault is to be cleared within 4 cycles $(2$ cycles, i.e. $0.5 \mathrm{~s}$ of relay operation plus 2 cycles, $0.5 \mathrm{~s}$ ). Hence the ROCOVPA can detect the fault condition within less than a cycle and island the microgrid in around 1s by tripping the circuit breaker, which is less than the 2s of the IEEE-1547 and UL-1741 standards. The same fault conditions were applied and tested with ROCOF in Matlab as shown in Figure 8 and the islanding was detected in $30 \mathrm{~ms}$. If the threshold value is fixed at $0.02 \mathrm{~Hz} / \mathrm{sec}$, the tripping of the circuit breaker can be actuated in around $1 \mathrm{~s}$ which is below the $2 \mathrm{~s}$ of the standards. The detection time of ROCOF is more than that of ROCOVPA. As the ROCOF is dependent on frequency, at lower \% power mismatches, the threshold value cannot be fixed exactly. Hence, the detection time varies inversely with \% power mismatch. To mitigate these issues, ROCOVPA was proposed and proved to be a better islanding detection method for unsymmetrical faults.

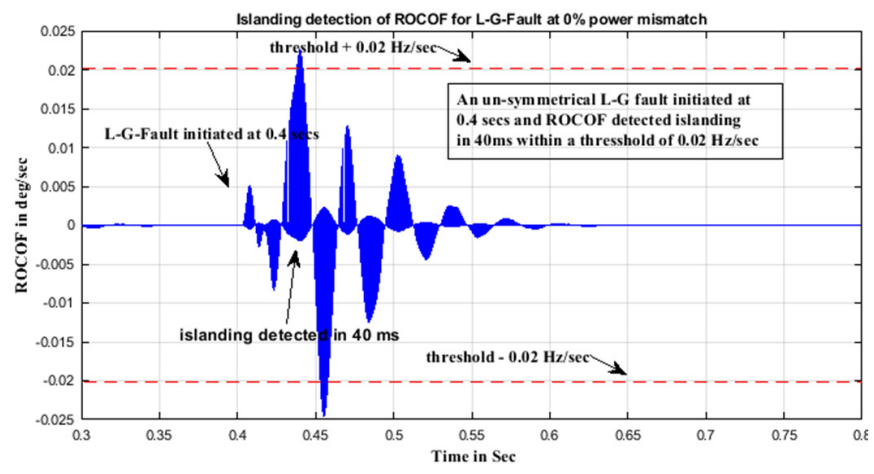

Fig. 8. Islanding detection of ROCOF for a L-G fault on the system.

\section{B. Non-Islanding Case for Non-Linear Load Connection and} Disconnection at the PCC on the System

System stability has been studied for different transient conditions during load connection and disconnection at the PCC with non-linear load for both ROCOVPA and ROCOF in Matlab/Simulink. Both methods proved their stability by avoiding nuisance tripping within the threshold values. The ROCOVPA threshold value is $1 \mathrm{deg} / \mathrm{s}$ and that of ROCOF is $0.02 \mathrm{~Hz} / \mathrm{sec}$.

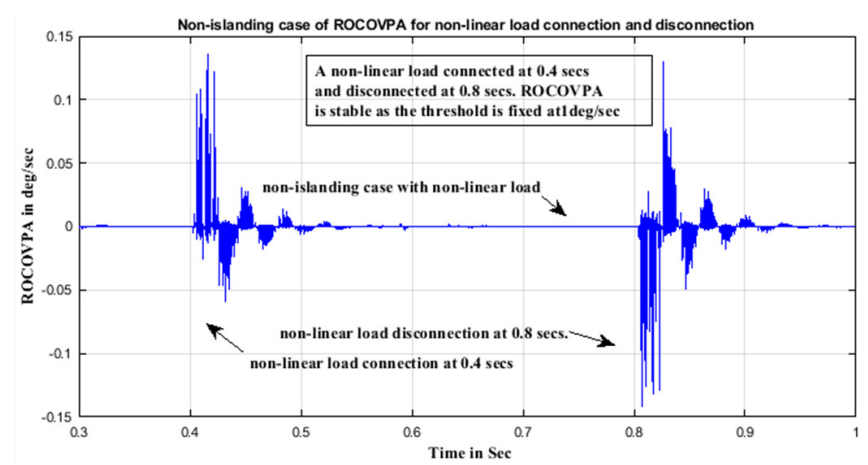

Fig. 9. Non-islanding case of ROCOVPA for non-linear load connection and disconnection.

A non-linear load was connected at the PCC at $0.4 \mathrm{~s}$ and was disconnected at $0.8 \mathrm{~s}$. The results of non-islanding scenerios of ROCOVPA and ROCOF are shown in Figures 9 and 10. The readings of ROCOVPA and ROCOF show that the thresholds are much higher. Hence, the system is stable without any nuisance tripping of the circuit breaker. 


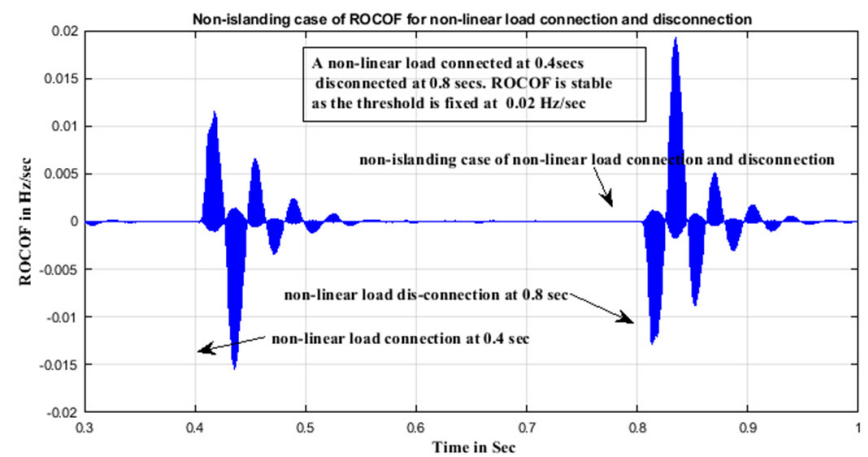

Fig. 10. Non-islanding case of ROCOF for non-linear load connection and disconnection.

\section{CONCLUSIONS}

Islanding detection is a major challenge when considering microgrids. The most common unintentional faults on the system are supposed to the be unsymmetrical L-G faults, in which one phase snapping and making phase to ground is involved. The proposed ROCOVPA passive islanding detection method was tested for islanding detection at $0 \%$ power mismatch $(0 \% \mathrm{NDZ})$ along with the widely used ROCOF and proved to be a better alternative having less detection time. The ROCOVPA method was also tested for its stability to avoid nuisance tripping during load connection and disconnection and found to be quite effective. It is also simple and faster in discriminating between islanding and non-islanding operations of the microgrid. The detection is more accurate as the phase angle does not depend on mismatched power like voltage and frequency relays. In the future, the proposed ROCOVPA method can be extended for the detection of symmetrical faults with hybrid DGs.

\section{ACKNOWLEDGMENT}

The authors wish to thank the faculty of Electrical and Electronics Department of Koneru Lakshmaiah Educational Foundation (Deemed to be University).

\section{FINANCIAL DISCLOSURE}

The authors declare that this research work received no financial support from anywhere.

\section{AUTHORS CONFLICT/COMPETING INTEREST}

The authors declare that there is no conflict/competing interest.

\section{REFERENCES}

[1] D. Milošević and Ž. Đurišić, "Technique for stability enhancement of microgrids during unsymmetrical disturbances using battery connected by single-phase converters," IET Renewable Power Generation, vol. 14, no. 9, pp. 1529-1540, 2020, https://doi.org/10.1049/iet-rpg.2019.0625.

[2] D. Kumar, "A Survey on Recent Developments of Islanding Detection Techniques," Turkish Journal of Electrical Power and Energy Systems, vol. 1, pp. 42-53, 2021, https://doi.org/10.5152/tepes.2021.21012.

[3] C. R. Reddy and K. H. Reddy, "Islanding detection for inverter based distributed generation with Low frequency current harmonic injection through Q controller and ROCOF analysis," Journal of Electrical Systems, vol. 14, no. 2, pp. 179-191, Jun. 2018.
[4] Y. Elshrief, A. Asham, S. Abdelhaleem, and B. Abozalam, "Methods for protecting Network from Islanding Danger," Journal of Engineering Research, vol. 9, no. 2, May 2021, https://doi.org/10.36909/ jer.v9i2.9695.

[5] M.-S. Kim, R. Haider, G.-J. Cho, C.-H. Kim, C.-Y. Won, and J.-S. Chai, "Comprehensive Review of Islanding Detection Methods for Distributed Generation Systems," Energies, vol. 12, no. 5, Jan. 2019, Art. no. 837, https://doi.org/10.3390/en12050837.

[6] M. Hosseinzadeh and F. Rajaei Salmasi, "Islanding Fault Detection in Microgrids-A Survey," Energies, vol. 13, no. 13, Jan. 2020, Art. no. 3479, https://doi.org/10.3390/en13133479.

[7] F. Namdari, M. Parvizi, and E. Rokrok, "A Novel Passive Method for Islanding Detection in Microgrids," Iranian Journal of Electrical and Electronic Engineering, vol. 12, no. 1, pp. 82-90, Mar. 2016.

[8] O. Tshenyego, R. Samikannu, and B. Mtengi, "Wide area monitoring, protection, and control application in islanding detection for grid integrated distributed generation: A review," Measurement and Control, Apr. 2021, Art. no. 0020294021989768, https://doi.org/10.1177/ 0020294021989768.

[9] P. Kumar, V. Kumar, and R. Pratap, "Design and verification of hardcore reconfigurable relay for islanding detection and subsequent mode adaptation of microgrid," International Transactions on Electrical Energy Systems, vol. 29, no. 4, 2019, Art. no. e2807, https://doi.org/10.1002/etep.2807.

[10] K. Rayudua, A. J. laxmi, P. Soumya, R. Pradeep, and T. Kochito, "Design of Controller for Transition of Grid Connected Microgrid to Island Mode," Turkish Journal of Computer and Mathematics Education, vol. 12, no. 2, pp. 845-854, Apr. 2021, https://doi.org/ 10.17762/turcomat.v12i2.1093.

[11] F. Chanaa et al., "Islanding Detection Method of a Photovoltaic Installation Destined to Power a RLC Load and Integrated to LV Network," International Journal of Intelligent Engineering and Systems, vol. 14, no. 4, pp. 299-311, Aug. 2021, https://doi.org/10.22266/ ijies2021.0831.27.

[12] E. Pathan, S. A. Zulkifli, U. B. Tayab, and R. Jackson, "Small Signal Modeling of Inverter-based Grid-Connected Microgrid to Determine the Zero-Pole Drift Control with Dynamic Power Sharing Controller," Engineering, Technology \& Applied Science Research, vol. 9, no. 1, pp. 3790-3795, Feb. 2019, https://doi.org/10.48084/etasr.2465.

[13] P. D. Chung, "Retaining of Frequency in Micro-grid with Wind Turbine and Diesel Generator," Engineering, Technology \& Applied Science Research, vol. 8, no. 6, pp. 3646-3651, Dec. 2018, https://doi.org/ 10.48084/etasr.2413

[14] M. Karimi, M. Farshad, Q. Hong, H. Laaksonen, and K. Kauhaniemi, "An Islanding Detection Technique for Inverter-Based Distributed Generation in Microgrids," Energies, vol. 14, no. 1, Jan. 2021, Art. no. 130, https://doi.org/10.3390/en14010130.

[15] R. S. Somalwar, D. A. Shinde, and S. G. Kadwane, "Performance Evaluation of Voltage Ripple-Based Passive Islanding Detection Method for a Single-Phase Utility-Connected Micro-Grid System," IETE Journal of Research, Nov. 2020, https://doi.org/10.1080/03772063.2020. 1844066.

[16] S. Dutta, P. K. Sadhu, M. Jaya Bharata Reddy, and D. K. Mohanta, "Shifting of research trends in islanding detection method - a comprehensive survey," Protection and Control of Modern Power Systems, vol. 3, no. 1, Jan. 2018, Art. no. 1 (2018), https://doi.org/ 10.1186/s41601-017-0075-8

[17] N. C. Munukutla, V. S. K. Rao Gadi, and R. Mylavarapu, "A Simplified Approach to Controlled Islanding of Power System," in 2019 8th International Conference on Power Systems (ICPS), Jaipur, India, Dec. 2019, https://doi.org/10.1109/ICPS48983.2019.9067725.

[18] J. Sridevi, V. U. Rani, and B. L. Rao, "Integration of Renewable DGs to Radial Distribution System for Loss Reduction and Voltage Profile Improvement," in 2019 1st International Conference on Electrical, Control and Instrumentation Engineering (ICECIE), Kuala Lumpur, Malaysia, Nov. 2019, https://doi.org/10.1109/ICECIE47765.2019. 8974670.

[19] S. Salee and P. Wirasanti, "Optimal siting and sizing of battery energy storage systems for grid-supporting in electrical distribution network," in 
2018 International ECTI Northern Section Conference on Electrical, Electronics, Computer and Telecommunications Engineering (ECTINCON), Chiang Rai, Thailand, Feb. 2018, pp. 100-105, https://doi.org/10.1109/ECTI-NCON.2018.8378290.

[20] B. Srinivasarao, S. Lalitha, and Y. Sreenivasarao, "Evaluation of ClosedLoop-P.I.D, Fractional-Order-P.I.D and Proportional Resonant Controlled Micro-Grid-Schemes," Journal of Computational and Theoretical Nanoscience, vol. 16, no. 5-6, pp. 2479-2487, May 2019, https://doi.org/10.1166/jctn.2019.7919.

[21] K. Subramanian and A. K. Loganathan, "Islanding Detection Using a Micro-Synchrophasor for Distribution Systems with Distributed Generation," Energies, vol. 13, no. 19, Jan. 2020, Art. no. 5180, https://doi.org/10.3390/en13195180.

[22] B. V. Rajanna and K. S. Srikanth, "Grid Connected Inverter for Current Control by Using Anti-Islanding Technique," International Journal of Power Electronics and Drive Systems (IJPEDS), vol. 9, no. 2, pp. 926932, Jun. 2018, https://doi.org/10.11591/ijpeds.v9.i2.pp926-932.

[23] M. K. Kumar, C. Veeranjaneyulu, and P. S. Nikhil, "Interfacing of distributed generation for micro grid operation," Journal of Advanced Research in Dynamical and Control Systems, vol. 10, no. 4, pp. 427$477,2018$.

[24] K. Jyothi, K. S. Srikanth, and H. S. Jain, "Control of stand alone and grid connected distributed energy resource: A review," Journal of Advanced Research in Dynamical and Control Systems, vol. 10, no. 12, pp. 1603-1615, 2018.

\section{AUTHOR PROFILES}

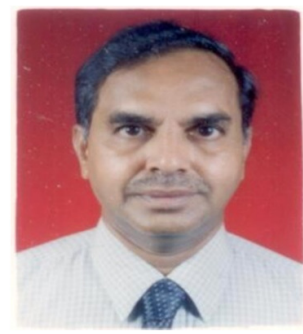

L. Bangar Raju is currently working as an Associate Professor in Swarna Bharati Institute of Technology, Khammam, Telangana State, India. He received his B.E. from the Jawaharlal Nehru Technological University, Kakinada, A.P. India and M.Sc. (Engineering) in Power Systems from the Calicut University. He has got 30 years of industrial experience in power, oil and gas, petrochemical, transmission, distribution, and utilization plants. He has published 10 international Scopus indexed papers. He is a Life Member of ISTE (India) and IE (India). He is currently pursuing his Ph.D. from the Koneru Lakshmaiah Educational Foundation (Deemed to be University), Guntur, A.P., India. His areas of interest are power system protection, distributed generation, and microgrids.

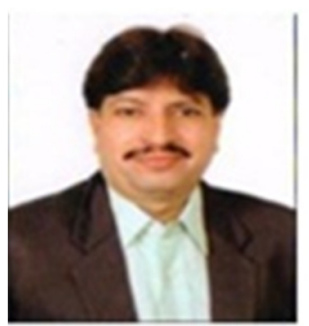

K. Subba Rao is presently the Principal at the College of Engineering and a Professor of Electrical and Electronics Engineering, Department of Koneru Lakshmaiah Educational Foundation (Deemed to be University), Guntur, A.P., India. He received his Ph.D. from Koneru Lakshmaiah Educational Foundation, M.Tech. from CIT, Coimbatore and B.Tech. from Dayalbagh University, Agra. He has earned the best teacher award10 times. He is a life member of ISTE and of the Indian Society for Quality. He has published national and international papers and a book. His areas of interest are power electronics, power systems, microgrids, and Security Systems 